\title{
Observation of Water Molecules Bound to a Protein Using Cold-Spray Ionization Mass Spectrometry
}

\author{
Yoshihisa SeI, ${ }^{* 1, * 2}$ Sakurako ShImotakahara, ${ }^{* 3}$ Juri ISHII, ${ }^{* 3}$ Heisaburo ShIndo, ${ }^{* 3}$ Hiroko SekI, ${ }^{* 4}$ \\ Kentaro YAMAGUCHI, $* 1, * 2 \dagger$ and Mitsuru TASHIRO $* 5 \dagger$
}

*1 Department of Pharmaceutical Technology, Faculty of Pharmaceutical Sciences at Kagawa Campus, Tokushima Bunri University, Shido, Sanuki-city, Kagawa 769-2193, Japan

*2 CREST, Japan Science and Technology Agency (JST), Japan

*3 School of Pharmacy, Tokyo University of Pharmacy and Life Science, Hachioji, Tokyo 192-0392, Japan

*4 Chemical Analysis Center, Chiba University, Yayoi, Inage, Chiba 263-8522, Japan

*5 Department of Chemistry, Faculty of Science, Tokyo Metropolitan University, Minami-Osawa, Hachioji, Tokyo 192-0367, Japan

\begin{abstract}
The characterization of water molecules bound to ribonuclease $T_{1}\left(R N a s e T_{1}\right)$ was carried out using cold-spray ionization mass spectrometry (CSI-MS). CSI-MS is a variant of electrospray ionization mass spectrometry (ESI-MS) operating at low temperature, and is particularly suitable for investigating the weaker molecular associations, since the temperature at the spray interface is much lower than that in the conventional ESI-MS. In this approach, ion peaks due to the addition of nine water molecules were identified at a spray temperature of $48^{\circ} \mathrm{C}$. This result showed good agreement with that inferred by the combinational analysis of NMR and X-ray crystallography, indicating that CSI-MS is capable of rapidly providing reliable information to characterize the number of water molecules bound to a macromolecule.
\end{abstract}

(Received January 6, 2005; Accepted February 9, 2005)

\section{Introduction}

Internal and ordered surface water molecules of biological molecules often play significant roles in stabilizing through the formation of bridging hydrogen-bonds in protein structures and in enzymatic mechanisms., ${ }^{1,2}$ Much effort has been made cocerning the kinetic and structural characterization of these water molecules. Although large numbers of water molecules are often identified in high-resolution X-ray crystal structures of proteins and nucleic acids, ${ }^{3,4}$ it is not possible to determine by $\mathrm{X}$-ray crystallography whether these water molecules arise from the crystal packing forces, or are intrinsic components of the macromolecules. Recent NMR methods to study the location of macromolecular bound water molecules in solution have taken advantage of the selective excitation of the water resonance; $2 \mathrm{D}$ ROESY-HMQC and ROESY-HSQC have been presented for ${ }^{15} \mathrm{~N}$ - or ${ }^{13} \mathrm{C} /{ }^{15} \mathrm{~N}$-enriched protein. ${ }^{5-8}$ However, these NMR methods are available only for proteins that can be largely expressed by using a recombinant system of isotopical enrichment. Herein, we present the characterization of macromolecular bound water molecules using cold-spray ionization (CSI) $)^{9,10}$ mass spectrometry, a variant of electrospray ionization $^{11-13}$ mass spectrometry (ESI-MS) operating at low temperature. Although ESI-MS and other mass spectrometry have been used for the detection of noncovalent macromolecular associations ${ }^{14-16}$ and the hydration of peptides

$\doteqdot$ To whom correspondence should be addressed.

E-mail: tashiro@nmr.chem.metro-u.ac.jp; yamaguchi@kph.bunri-u.ac.jp and proteins, ${ }^{17-19}$ it has been shown that CSI-MS is more sensitive for observing weaker associations among proteins, since the temperature at the spray interface is much lower. The efficiency of this approach was demonstrated in a study of the water molecules bound to ribonuclease $\mathrm{T}_{1}\left(\mathrm{RNase} \mathrm{T}_{1}\right)$. RNase $\mathrm{T}_{1}$ has been a target of extensive biochemical and biophysical studies, and several approaches have been used to study water molecules bound to RNase $T_{1}$, including, protein engineering, $\mathrm{X}$-ray crystallography and NMR. ${ }^{20,21}$ Taking advantage of past studies concerning RNase $T_{1}$, the reliability of the approach in a study of bound water molecules using CSI-MS was investigated.

\section{Experimental}

\section{Expression and purification of RNase $T_{I}$}

Recombinant RNase $\mathrm{T}_{1}$ was expressed in $E$. coli strain HMS174(DE3) grown at $37^{\circ} \mathrm{C}$ in $\mathrm{M} 9$ medium using the expression vector pET25b (Novagen). Overexpression of RNase $\mathrm{T}_{1}$ was induced at an $\mathrm{OD}_{600}$ of 0.5 by adding isopropyl-1thio- $\beta$-D-galactopyranoside (IPTG) to a final concentration of $0.5 \mathrm{mM}$. The fermentor was then thermostated to $30^{\circ} \mathrm{C}$ for an additional $14-16 \mathrm{~h}$. The cells were harvested by centrifugation. The recombinant RNase $T_{1}$ was released from the periplasmic space by an osmotic shock treatment, and purified using a Sephadex-75 column $(1.6 \times 60 \mathrm{~cm})$ (Amersham Biosciences).

\section{CSI-MS}

CSI-MS measurements were performed using a time-of-flight 

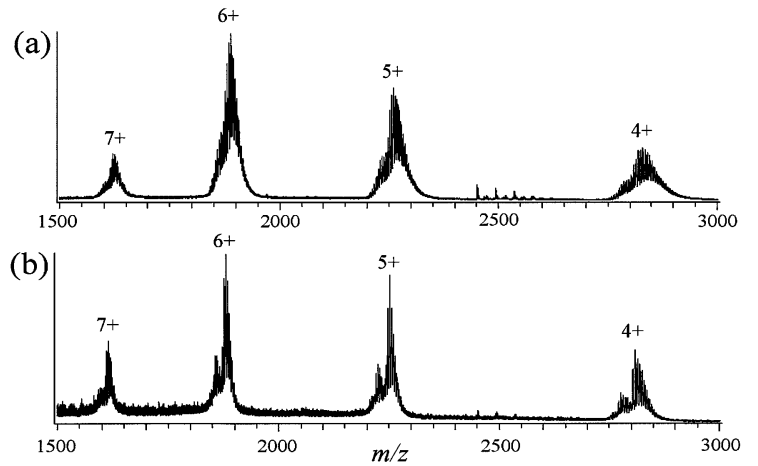

Fig. 1 CSI-MS spectra of RNase $\mathrm{T}_{1}$ with $10 \mathrm{mM}$ of $\mathrm{NH}_{4} \mathrm{OAc}(\mathrm{pH}$ 7.5) at spray temperatures of (a) 48 and (b) $115^{\circ} \mathrm{C}$.

mass spectrometer (JEOL JMS-T100) equipped with an orthogonal CSI source. An orthogonal cold-spray apparatus equipped with a spray- and ion-source temperature control system using liquid $\mathrm{N}_{2}$ was used. A thermocouple was equipped at the inlet of the extraction orifice, which is considered to be an ion-generating point in this orthogonal coldspray instrument. The temperatures at this point were defined as the spray temperature. A schematic diagram of the cold spray ionization source was described previously. ${ }^{10}$ The measurement conditions and the sample-preparation procedures were as follows: acceleration voltage, $2.0 \mathrm{kV}$; needle voltage, $1.4 \mathrm{kV}$; orifice voltage, $193 \mathrm{~V}$; resolution, 6000; spray temperature, $48-115{ }^{\circ} \mathrm{C}$; sample flow rate, $8.5 \mu \mathrm{L} / \mathrm{min}$; $0.1 \mathrm{mM}$ RNase $\mathrm{T}_{1}$ dissolved in $10 \mathrm{mM} \mathrm{NH} \mathrm{m}_{4} \mathrm{OAc}(\mathrm{pH}$ 7.5). The spectra were obtained via the infusion of RNase $\mathrm{T}_{1}$ through the coldspray interface in the positive ionization mode.

\section{Results and Discussion}

The CSI mass spectra of RNase $\mathrm{T}_{1}$ at spray temperatures of 48 and $115^{\circ} \mathrm{C}$ are shown in Fig. 1. Under these conditions, RNase $\mathrm{T}_{1}$ generated envelopes of ions between $\mathrm{m} / \mathrm{z}, 1500$ and 3000, corresponding to $7+$ through $4+$ charge states. Expansions of the $6+$ ion peaks measured at spray temperatures of 48 and $115^{\circ} \mathrm{C}$ are shown in Fig. 2. Most of the ion peaks were observed as sodium adducts. Interestingly, two envelopes of ions, which were more evident at a higher spray temperature of $115^{\circ} \mathrm{C}$, were observed. At a spray temperature of $115^{\circ} \mathrm{C}$, one of the envelopes of ions between $\mathrm{m} / \mathrm{z}, 1855$ and 1870 at the 6+ charge state corresponded to RNase $\mathrm{T}_{1}$ bound with one to two water molecules. The other envelope between $\mathrm{m} / \mathrm{z}, 1873$ and 1893 corresponded to seven to eight water molecules, and peaks due to the addition of up to eight water molecules were clearly identified (Fig. 2b). At a spray temperature of $48^{\circ} \mathrm{C}$, one of the envelopes of ions between $\mathrm{m} / \mathrm{z} 1855$ and 1873 corresponded to RNase $\mathrm{T}_{1}$ bound to two water molecules. This observation was slightly different from that at a spray temperature of $115^{\circ} \mathrm{C}$. Peaks due to the addition of just one water molecule were present only at a high spray temperature, which is considered to be the result of desolvation. The other envelope between $\mathrm{m} / \mathrm{z}$ 1873 and 1908 corresponds to seven to nine water molecules (Fig. 2a). A measurement at the lower spray temperature of $48^{\circ} \mathrm{C}$ could detect one additional bound water molecule.

Solvation in the CSI-MS measurement was investigated for a small ionic molecule, cesium iodide (CsI), in an acetonitrile solution. ${ }^{9}$ The molecular ions of $\mathrm{Cs}^{+}$and $\left[\mathrm{Cs}+\mathrm{CH}_{3} \mathrm{CN}\right]^{+}$formed (a)

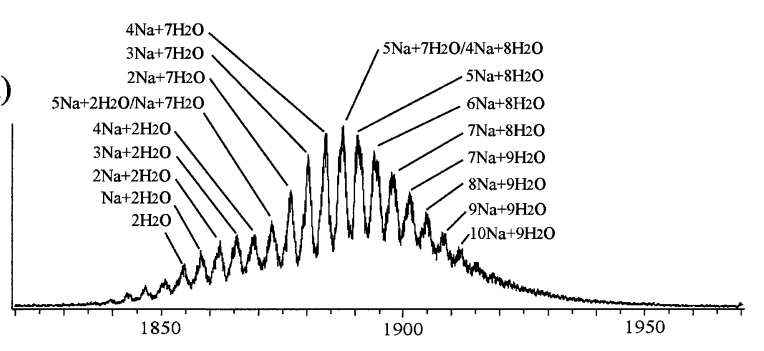

(b)

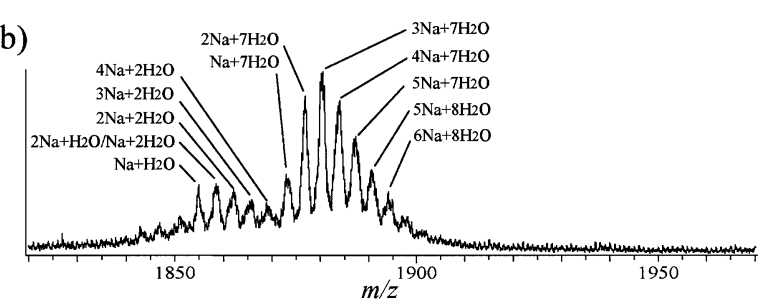

Fig. 2 Expansions of the $6+$ ion peak of RNase $T_{1}$ measured at spray temperatures of (a) 48 and (b) $115^{\circ} \mathrm{C}$. The number of water molecules correspond to $\left[\mathrm{RNase} \mathrm{T}_{1}+\mathrm{mNa}+(6-\mathrm{m}) \mathrm{H}+\left(\mathrm{H}_{2} \mathrm{O}\right)_{\mathrm{n}}\right]^{6+}$. The numbers of sodium atom and water molecules are indicated at each ion peak. Peaks due to the addition of water molecules are apparent.

by heat and solvation, respectively, were almost equally observed in the ESI-MS measurement, while the molecular ion of $\left[\mathrm{Cs}+\mathrm{CH}_{3} \mathrm{CN}\right]^{+}$was dominantly observed in the CSI-MS measurement. The solvation of adamantanoid type $\mathrm{Pt}(\mathrm{II})$ complexes was also compared in the ESI-MS and CSI-MS measurements. ${ }^{9}$ Multiple charged molecular ions of $\left[\mathrm{M}-\left(\mathrm{PF}_{6}\right)_{\mathrm{n}}\right.$ $\left.+\left(\mathrm{CH}_{3} \mathrm{CN}\right)_{\mathrm{m}}\right]^{\mathrm{n}+}(n=3-10, m=0-21)(\mathrm{M} ;$ monomeric molecule $)$ were clearly observed without decomposition only in the CSIMS measurement. Considering the above results, multiply charged molecular ions of a protein with bound waters are highly expected to be observed in the CSI-MS, which uses new ion sources operating at low temperature.

The hydration of RNase $\mathrm{T}_{1}$ was fairly investigated by NMR using ${ }^{13} \mathrm{C} /{ }^{15} \mathrm{~N}$-enriched proteins. ${ }^{20}$ In this research, 2D heteronuclear NOESY-HSQC and ROESY-HSQC experiments were performed with $2.0 \mathrm{mM}$ RNase $\mathrm{T}_{1}$ in $92 \% \mathrm{H}_{2} \mathrm{O} / 8 \% \mathrm{D}_{2} \mathrm{O}$ at $\mathrm{pH} 5.5$ to determine the spatial proximity of water molecules; the backbone carbonyl oxygens involved in the intermolecular hydrogen bonds to water molecules were identified based on the ${ }^{1} J_{\mathrm{NC}^{\prime}}$ coupling constants. Ten amide protons and five aliphatic proton groups cross-relaxing with bound water protons were identified. An examination of the high-resolution $(1.5 \AA)$ crystal structure of RNase $\mathrm{T}_{1}{ }^{22}$ revealed that all of these protein protons donate hydrogen bonds, or are in close proximity $(\sim 3.5$ $\AA$ ) to twelve water molecules that must reside for at least several hundred picoseconds, indicating that these amide/aliphatic protons are highly correlated with the bound water molecules. Besides these twelve bound water molecules, twenty-nine water molecules were classified as ambiguous bound waters, since the possibility of ROE (rotating frame NOE) interactions between protein protons and rapidly exchanging protons could not be excluded. The numbers of water molecules obtained by CSI-MS measurements were nine and eight at spray temperatures of 48 and $115^{\circ} \mathrm{C}$, respectively. Considering the difference of the sample solutions used in NMR and CSI-MS measurements, the results of CSI-MS are in good agreement with that inferred by the combinational analysis of NMR and X-ray crystallography.

Although the location of water molecules at the binding sites cannot be determined by mass spectrometry, it would be worth 
noting the potential bound water molecules of RNase $T_{1}$ observed in the CSI-MS measurements. In a combinational analysis of NMR and X-ray crystallography, twelve water molecules were classified as bound water molecules. ${ }^{20}$ Six of twelve water molecules (W106, W107, W108, W110, W135, $\mathrm{W} 166)$ are positioned in close proximity to the hairpin-like loop 3 (L3) comprising residues 62 to $76 .{ }^{22}$ Two strands of the loop are connected together by a chain formation of water molecules (W107, W108 and W110) with low-temperature factors, anchored at $\operatorname{Trp59}\left(\mathrm{N}^{\varepsilon} \mathrm{H}\right)$. Two of these (W107 and W108) are considered to bind tightly owing to their multiple contacts to the protein. Water molecule W107 accepts two hydrogen bonds from $\operatorname{Trp} 59\left(\mathrm{~N}^{\varepsilon} \mathrm{H}\right)$ and Tyr68(NH), and donates a hydrogen bond to Pro60(O). W108 accepts a hydrogen bond from Leu62(NH) and donates it to Asp66(O). Two bound water molecules identified in the envelope of ions between $\mathrm{m} / \mathrm{z} 1855$ and 1873 (Fig. 2a) could correspond to W107 and W108.

Since the detection of water molecules by NMR depends on observing the correlation between protons of protein and those of water molecules, complete assignments of the backbone and the side-chain are inevitable. Any ambiguity of the assignments or an overlapping of the cross peaks in the NMR spectra could lead to a misinterpretation, which would make a detailed analysis significantly difficult for larger proteins and nucleic acids. The present results indicate that CSI-MS is capable of rapidly providing reliable information to characterize the number of water molecules bound to a macromolecule. Although the location of hydration sites cannot be determined by CSI-MS, this method is highly amenable to the quick interpretation of bound water molecules associated to proteins of which the expression level and solubility are low, and to a better understand the functional role of water in macromolecules. MS measurements at low solution temperature will be favored for observing biomolecules under physiological conditions.

\section{Acknowledgements}

This study was supported by a Grant-in-Aid for Scientific Research (No. 13557198, 14571995 and 15550076) from the Ministry of Education, Culture, Sports, Science, and Technology. K. Y. is responsible for the CREST project of the Japan Science and Technology Agency (JST).

\section{References}

1. E. Westhof, Int. J. Biol. Macromol., 1987, 9, 186.

2. E. Westhof, Annu. Rev. Biophys. Biophys. Chem., 1988, 17, 125.

3. T. A. Steitz, Q. Rev. Biophys., 1990, 23, 205.

4. E. N. Baker and R. E. Huddard, Prog. Biophys. Mol. Biol., 1984, 44, 97.

5. R. Kriwacki, R. B. Hill, J. M. Flanagan, J. P. Caradonna, and J. H. Prestegard, J. Am. Chem. Soc., 1993, 115, 8907.

6. M. Tashiro, K. Furihata, S. Shimotakahara, and H. Shindo, Magn. Reson. Chem., 2002, 40, 559.

7. S. Grzesiek and A. Bax, J. Am. Chem. Soc., 1993, 115, 12593.

8. S. Grzesiek and A. Bax, J. Biomol. NMR, 1993, 3, 627.

9. S. Sakamoto, M. Fujita, K. Kim, and K. Yamaguchi, Tetrahedron, 2000, 56, 955.

10. K. Yamaguchi, J. Mass Spectrom., 2003, 38, 473.

11. J. B. Fenn, M. Mann, K. Meng, S. F. Wong, and C. M. Whitehouse, Science, 1989, 246, 64.

12. P. Kebarle and L. Tang, Anal. Chem., 1993, 65, 972A.

13. A. P. Bruins, J. Chromatogr., 1998, A794, 345.

14. R. D. Smith and K. J. Light-Wahl, Biol. Mass Spectrom., 1993, 22, 493.

15. Y. T. Li, Y. L. Hsieh, J. D. Henion, M. W. Senko, F. W. McLafferty, and B. Ganem, J. Am. Chem. Soc., 1993, 115, 8409.

16. J. A. Loo, D. D. Holsworth, and R. S. Root-Bernstein, Biol. Mass Spectrom., 1994, 23, 6.

17. J. Woenckhaus and R. R. Hudgins, J. Am. Chem. Soc., 1997, 119, 9586.

18. S. E. Rodriguez-Cruz, J. S. Klassen, and E.R. Williams, J. Am. Soc. Mass Spectrom., 1999, 10, 958.

19. D. Liu, T. Wyttenbach, P. E. Barran, and M. T. Bowers, J. Am. Chem. Soc., 2003, 125, 8458.

20. S. Pfeiffer, N. Spitzner, F. Löhr, and H. Rüterjans, J. Biomol. NMR, 1998, 11, 1.

21. U. Langhorst, R. Loris, V. P. Denisov, J. Doumen, P. Roose, D. Maes, B. Halle, and J. Steyaert, Protein Sci., 1999, 8,722 .

22. J. Martinez-Oyanedel, H. W. Choe, U. Heinemann, and W. Saenger, J. Mol. Biol., 1991, 222, 335. 